\title{
Markers characterizing corneal damage during aging of rat
}

\author{
Hassan I. H. El-Sayyad *†, Ahmed A. El-Mansi, Mona S Guida * and
}

Ezaldin AM Mohammed**

†Department of Zoology, Faculty of Science, Mansoura University, Mansoura 002050 2254850, Egypt

elsayyad@mans.edu.eg.

* Department of Pediatrics, Faculty of Medicine, Mansoura University, Mansoura, Egypt

** Department of Zoology, Faculty Science, Omar Al- Mokhtar University, Libya.

\section{Ezaldin76@yahoo.com.}

${ }^{*}$ †Corresponding author: ${ }^{*}$ †Department of Zoology, Faculty of Science, Mansoura University, Mansoura 002050 2254850, Egypt

elsayyad@mans.edu.eg.

\begin{abstract}
Aging is a biological phenomenon that involves an increase of oxidative stress associated with gradual degradation of the structure and function of the cornea. Gender differences and subsequent deterioration of cornea is an interesting topic, especially yet few data are available concerning the impact of age, especially on the comeal. One hundred male and female Wistar albino rats ages $3,6,18,24$, and 30 months ( $n=10$ equal for male and female) were used. At the time interval, cornea were investigated by light and transmission electron microscopy (TEM), immunohis tochemistry of cas pase 3 (casp3), glial fibrillar acidic protein(GFAP) and CD45 and flow cytometry of DNA, bcl-2-like protein 4 (BAX), transfoming growth factor beta (TGF- $\beta$ ) and Cd45 (lymphocyte common antigen). Light and TEM investigation revealed apparent deterioration of atrophy of corneal epithelium with vesicular vacuolar degeneration, hyalinization of stromal collagen fibrils and swelling and degeneration of the endothelial lining the descemet's membrane. There was apparent loss of keratocytes within corneal stroma. Immunohistochemistry of casp 3 and CD45 were markedly increased manifesting cell damage. GFAP showed apparent reduction of innervation of corneal stroma and endothelium layer. Flow cytometry of DNA, Bax and TGF revealed increas ed apoptic cell death of cornea of 30M-old rats. We concluded that aging contributed to an apparent increase of cellular damage of different corneal region associated with alterations of cell markers.
\end{abstract}

Keywords: Aging, cornea, immunohistochem istry, flow cytometry, transmission electron microscopy.

\section{Council for Innovative Research}

Peer Review Research Publishing System

Journal: Journal of Advances in Chemistry

Vol. 11, No. 5

editorjaconline@gmail.com

www.cirjac.com 


\section{Introduction}

The cornea forms the anterior surface of the eye in an area largely corresponding to the pigmented iris, which is visible behind the cornea. Aging, a biological phenomena involve intemal physiological deterioration of the multicellular organisms [1].

In humans, aging is usually monitored in relation to time, which renders it difficult to differen tiate between time dependent biological changes and damage from environmental insults [1]. Corneal aging produces both structural and functional changes. These changes in tum can affect the ability of the organ to refract light, to repair and protect itself as well as the internal structures of the eye [2]. A variety of corneal aging changes have been reported. However, as it is difficult to distinguish age specific deterioration from degenerations modified by environmental and genetic factors. Corneal opacity is a common feature of aging in the human eye and is due to deposition of lipids in the peripheral comeal stroma. The arcus has a hazy gray-white appearance, a sharp outer margin but an indistinct inner border [3] .

The cornea and blood vessels are both composed of connective tissue in the middle zone, namely the corneal stroma and the media of the artery, containing a single cell type: fibroblasts and smooth muscle cells respectively. Lipid deposition in the cornea is visible and more readily studied, which adds extra interest to what is happening in the cornea [3] . Reports have also linked corneal arcus with diabetes mellitus, high blood pressure, smoking, and obesity $[4,5]$. However, these associations remain controversial.

There are very little informations about aging related changes of the of comea as well as their cell markers involved in their cell degradation. The present study aimed to illustrate the cell markers of age-related comeal damage during aging progress of Wistar rats taking in consideration the histo-cytological changes, immunohistochemistry of casp3,GFAP and Cd45 and flow cytometry of cell cycle and BAX, TGF and CD45.

\section{Materials and Methods}

One houndred male and females Wistar albino rats (Rattus novergicus) at 3, 6, 18, 24, and 30-M (months) old were obtained from Hellwan Breeding Farm, Ministry of Health, Cairo, Egypt, and used for experimentation. During accommodation and growth, the animals were maintained in an aerated room at constant 12 -h of light and dark cycle with intensity light exposure at 180-200 Ix. They had free excess to standard diet and water ad libitum. The animals were sacrificed by light chloroform anesthesia at 1, 6, 18,24, and 30 months old and dissected, the cornea were separated and subjected for investigation.

\section{Light microscopic investigations:}

Cornea of 3, 6, 18, 24 and 30M-old Wistar rat were incised immediately from the ocular region, fixed in $10 \%$ phosphate buffered formalin ( $\mathrm{pH} 7.4$ ), dehydrated in ascending grades of ethyl alcohol, cleared in xylol, and mounted in molten pararplast $58-62{ }^{\circ} \mathrm{C}$. Serial $5 \mu \mathrm{m}$ thick sections were cut and stained with hematoxylin and eosin (H\&E), examined under bright field light microscopy, and photographed.

\section{Transmission electron microscopy:}

Extra cornea specimens of $30 \mathrm{M}$-old rats were separated and immediately fixed in $2 \%$ glutaraldhyde and $2 \%$ paraformaldhyde in $0.1 \mathrm{M}$ cacodylate buffer $(\mathrm{pH} 7.4)$. After rinsing in $0.1 \mathrm{M}$ cacodylate buffer, the specimens were postfixed in a buffered solution of $1 \%$ osmium tetraoxide at $4{ }^{\circ} \mathrm{C}$ for $1.5 \mathrm{~h}$, dehydrated in ascending grades of ethyl alcohol, and embedded in epoxy resin. Ultrathin sections were cut with a LKB Ultratome IV (LKB Instruments, Bromma, Sweden) and mounted on grids, stained with uranyl acetate and lead citrate, and examined on a Joel 100CXI transmission electron microscope (Musas hino 3-chome; Akis hima, Tokyo, Japan).

\section{Immunohistochemistry of casp 3, GFAPand CD 45:}

The corneal tissues were fixed in $10 \%$ buffered formalin $(\mathrm{pH} 7.4)$ for $24-36 \mathrm{~h}$ before embedding in paraffin. Serial sections of $5 \mu \mathrm{m}$ in thickness were cut and individually mounted onto super frost plus glass slides (Fisher Themo Scientific, Nepean, Ontario, Canada). The tissue sections were retained at normal room temperature and were processed for antigen retrieval by digestion in $0.05 \%$ trypsin $\left(\mathrm{pH} \mathrm{7.8)}\right.$ for $15 \mathrm{~min}$ at $37{ }^{\circ} \mathrm{C}$ and incubated with antibodies against CD45 (Themo Fis her Scientific, Fremont, CA, USA; Cat. No. A1-70007), anti-mouse antibody of caspase-3 (DAKO, clone MIB5, 1:50, mouse) and 1/150 for mouse anti-GFAP (GFAP clone GA-5) (Sigma-Aldrich) for overnight at $4{ }^{\circ} \mathrm{C}$. A horseradish peroxidase streptavidin detection system (Dako), followed with DAB plus Chromagen to detect the immunoactivity, was followed by counterstaining with Mayer haematoxylin. Sections incubated with $1 \%$ nonimmune serum phosphate buffer solution (PBS) solution served as negative controls. Specimens were observed with a Leica BM5000 micros cope (Leica Microsystems, Wetzlar, Germany) and photographed.

\section{Flow cytometric analysis of cell cycle and BAX, TGF and CD45:}

Flow cytometric analys is was performed on FACScan (Becton Dickinson) using standard settings: fluorescence 1 (FL1), 4 decades (logarithmic), detector $648 \mathrm{~V}$, log amplifier, compensation 1.1\%; fluorescence 2 (FL2), 4 decades (logarithmic), detector $496 \mathrm{~V}$, log amplifier, compensation 22.8\%. Data analys is was performed using lys is software (Becton Dickinson). Biopsies from cornea at the selected ages were taken, and cell suspension was prepared with Tris -EDTA buffer (pH 74) (Sigma-Aldrich Co.). Cell suspension was fixed in ice-cold $96-100 \%$ ethanol (Sigma) at $4{ }^{\circ} \mathrm{C}$ overnight, centrifuged at $1,500 \mathrm{rpm}$ for $10 \mathrm{~min}$, and then resuspended in PBS containing $50 \mu \mathrm{g} / \mathrm{mL}$ propidium iodide (PI) (Sigma-Aldrich Co.). For each sample, since analysis was based on measurement of 10000 cells. Single cell suspensions were prepared from 
cornea from at least five rat of each of the each of the aging animals, and $1.5-3 \times 10^{6}$ cells were stained for expression of the designated lineage markers, with the following antibodies obtained from Pharmingen as mentioned.

Cell cycle analysis: Cell cycle analysis was performed by flow cytometry. Cells were harvested by centrifugation, washed in ice-cold PBS, and fixed in $80 \%$ ethanol that had been prechilled to $220^{\circ} \mathrm{C}$. Fixed cells were stored at $4^{\circ} \mathrm{C}$ for up to $1 \mathrm{wk}$. They were then repelleted and resuspended at a concentration of $0.1-0.310^{6} / \mathrm{ml}$ in PBS containing $18 \mathrm{mg} / \mathrm{ml} \mathrm{propidium}$ iodide (PI; Sigma) and $8 \mathrm{mg} / \mathrm{mI}$ RNase A (Sigma; PI solution). After incubation in the dark for at least $1 \mathrm{~h}$, cell cycle profil e analysis was performed on 10,000-20,000 cells on a FACSort flow cytometer using the Cellquest analysis program (Becton Dickinson, Sunnyvale, CA, USA).

BAX: The cells were permeabilized in saponin-containing buffer and incubated at room temperature for $30 \mathrm{~min}$ with $20 \mu \mathrm{L}$ of unconjugated anti-Bax antibody at a 1: 10dilution. Cells were further washed and incubated for $30 \mathrm{~min}$ with $100 \mu \mathrm{L}$ goat anti-mouse IgG FITC-conjugated second antibody (dilution 1: 100). Negative controls were performed by incubating cells with non-specific isotypic antibody at the corresponding dilution. The percentage of Bax-positive cells was assayed.

TGF- $\beta$ : The method applied for a 50-100 $\mu$ of cornea containing approximately $0.5-1 \times 10^{6}$ cells. The cells rinsed with PBS to remove serum proteins prior to antibody staining and incubated on ice with minimal light exposure. The sample ( $100 \mu \mathrm{l}$ of suspended cells) treated with $1 \mu \mathrm{g}$ of Fc Block antibody and incubate on ice for 20 minutes. Owing to its spectral characteristics TGF can be combined with fluorescein-isothiocyanate (FITC) and phycoerythrin (PE) cell surface staining. After staining, the samples can be treated with $1 \%$ parafomaldehyde solution in PBS to preserve the cells through and stored in the dark in the refridgerator. For flow cytometric apoptosis assay, $1 \times 10^{6}$ cells were stained with FITC-labeled TGFB and propidium iodide and were analyzed by FACS. Data are shown from a representative experiment with five different healthy donors.

CD45: A sample stained with CD45-FTTC was submitted to cell sorting on the basis of CD45 presence or absence using a FACS IV cell sorter (Becton Dickinson). Aliquots from each sorted population were cytospun into a monolayer using cytospin 3 (Shandon, Runcom, Cheshire, UK) and stained with Wright staining.

5. Statistical analysis: All discrete values, expressed as the meantstandard error (SE) were analyzed by using the two-tailed independent Student's $t$-test for unpaired samples after confirming the homogeneity of variances. The results presented below include comparisons between the first age ( 3 months) and the corresponding 6,18,24 and 30M-old. P values of $<0.05$ were considered to show significant differences.

\section{Results}

\section{Light and transmission electron microscopy:}

At light microscopic level, 3 \& 6M-old rat, the corneal cell layers are normally oriented with characteristic non-keratinized peripheral stratified epithelium. Their basal layer appeared columnar. The corneal epithelium appeared resting on a uniform basement membrane underneath it was the Bowman's layer. The corneal stroma consists of regularly oriented collagen fibrils infiltrated by Flattened keratocytes. The regularity of the collagen fibers are account for the transparency of the cornea. Descemet's membrane with underlying Descemet's endothelium located beneath the stroma (Fig.1 $A, A 1, B, B 1)$

The corneal epithelium become desquamated at 18M-old and showed apparent flattening in 24 month-old (Fig. 1C\&C1).

At $24 \mathrm{M}$-old, there were a considerable reduction of the comeal epithelium. Many of the epithelial cell become vacuolated and infiltrated by cytoplasmic vacuoles of different sizes more abundant in the females. The stromal connective tissue become hyalinized with characteristic eosinophilia and a decrease of keratocytes. The comeal endothelium lining the descemet's membrane become thickened (Fig.1 D\&D1).

At $30 \mathrm{M}$-old months old, the epithelium attained a considerable reduction with detected increase of mitotic figures especially of the basal cells. Many of the epithelial cells possessed either vesicular or pyknotic nuclei. There was a comparative reduction of cell density. The stroma showed patches of eosinophilic hyaline degenerated collagenous fibrils. The corneal endothelium attained a considerable thickening with deranged most of their endothelial lining cell. Both sex were equally affected (Fig.1 E\&E1).

At ultrastructural level, the $30 \mathrm{M}$-old aged rat showed apparent vacuolar degeneration and karyolys is of many of the epithelial cells (Fig. B). Many of the keratocytes showed degenerated and pleomorphic nuclei with compacted electrondense chromatin materials. The stromal fibrils lacked regular pattern with almost necrosis and edematic lesions (Fig. B1). There was a detected degeneration of the endothelium layer (Fig. 2 A-C1).

\section{Immuno staining of Caspase3, GFAP and CD 45:}

Intense expression of caspase 3 was detected within the basal epithelium reflecting increased apoptic rates as well as comparative reduction of GFAP in stoma and endothelium of 30M-old rats in comparison with 6M-old (Fig.3). Also,CD45 positive cells were distributed in irregular fas hion in peripheral stroma layer as well as in the basal-cell layer of the corneal epithelium and partly in the wing/surface layers especially of old 30M-old female rats comparing with the 6M-old (Fig.3 C1). 


\section{Flow cytometry of cell cycle, Bax, TGF-B and CD45:}

From table (1) and fig. (4), there was a considerable increase of M1 (subG1 apoptsis), Bax, TGF-B and Cd45 in 24 and 30-month-old rats.

\section{DISCUSSION}

The corneal epithelium undergoes dynamic turnover due to the sustained proliferation of basal epithelial cells [6,7].

From the present studies, the nomal pattern of corneal epithelium is appeared in the form of stratified squamous non keratinized layer having several cell layers thick. Aging related damage was firstly appeared in $24 \mathrm{M}$-old rats especially in females which revealed comparative reduction of corneal epithelium infiltrated by vacuoles of different sizes. At 30M-old, mitotic figures and vacuolar degeneration were remarked within the basal epithelial layer. Ultrastructurally revealed apparent vacuolar degeneration and karyolysis of many of these cells. The epithelial layer attained a comparative flattening and comparatively reduction in thickness.

The present findings supported the work of Galgauskas et al. [8], Yang et al. [9] and Grossniklaus et al.[10] whom revealed flattening and reduction of corneal epithelial thickness in age-related patients. Experimental 24- to 34-month-old old WT mice was found also to show decreas ed cell density and increased of cell size [11].

Also, the corneal stroma represents the important region which gives the cornea its characteristic structure and transparency. It is formed of regularly organized collagen fibrils infiltrated by keratocytes. In old rat $30 \mathrm{M}$-old, the stroma become eosinophilic with apparent hyaline degenerated collagenous fibrils and reduction of keratocytes especially in aged females. However aged male rats possessed folding and widespread of necrotic foci of their collagenous fibrils.

Similar changes were detected in aged men and women characterized by the presence of anterior stromal microdots and folds in the posterior stroma [12].

Daxer et al.[13] reported fragility of the stromal fibrils and spacing expansion resulting from glycation-induced crosslinking and reduction of the molecular tilting angle within collagen fibrils.

Also, our findings reported that the old rat $30 \mathrm{M}$-old exhibited apparent thickening of Descemet's membrane (DM) associated with loss many of their endothelial lining cells.

Jun et al. [14] attributed the thickening of DM during aging of mouse to the accumulation of the posterior, non-banded layer. Hillenaar et al.(2012) reported opacification of DM and corneal guttae as a cons equences of endothelial damage.

The endothelial lining layers play an important function in maintaining transparency of the stroma through pumping water out. Massive reduction of endothelial cells led to disruption of this pumping activity and impairing visual activity [15] .

Our histopathological findings were confimed by the assessments of flow cytometric analysis of increase M1 (sub-G1 apoptsis) as well as increase of BAX, TGF-b and decrease of CD45 (Fig.4). Elderly patients generally had higher caveolin-1 levels in the corneal epithelia than young patients manifesting increase average of cell damage [16] .

The observed increase of TGF-b in aged cornea reflecting increase of apoptic death.

The TGF-b1 is an important immunomodulatory cytokine in the immune system (Letterio and Roberts, 1998) and increased level was found to apoptos is in human primary B Iymphocytes (Spender et al.,2009) and basal layer cell lines [17].

Increased apoptosis of T cells has been reported in the airways in chronic obstructive pulmonary disease, in unbalanced cellular homeostasis, and prolongation of the inflammatory response. Via increase of tumor growth factor (Hodge et al.,2003). The TGF-b/TGFR pathway increased apoptos is of peripheral blood T cells by inhibiting proliferation at G1-S phase transition [18].

Also, BAX is a member of the Bcl-2 family of proteins known to regulate mitochondria-dependent programmed cell death. Bax leaves the mitochondrial membranes and coalesces into large clusters containing thousands of Bax molecules that remain adjacent to mitochondria. Also, The Bax protein was present in $25.6 \%$ of epithelial cells in macular dystrophy corneas but was absent in controls [19]. Increased BAX expression was parallel with increased DNA damage in the epithelium, stroma, and endothelium of corneas with Fuchs dystrophy [20]. Ritchey et al.[21] provided evidence for scarinduced accumulations of CD45-positive monocytes in injured chick corneas. Immunostaining of CD45 in trigeminal stereotactic electrolys is mice was found to reveal intense expression in inflamed and neovascularized corneal epithelium [22]

Ultraviolet-exposure was found to showed a significantly higher number of cells positively stained for CD45 [23] .

These findings supported the work of Joyce et al. [24] who mentioned age-related increase in oxidative nuclear DNA damage by forming DNA damage repair foci by DNA damage-signaling genes. Behndig et al. [25] and Behndig [26] reported the extracellular SOD was found in the epithelium, stroma, and endothelium. The concentration of extracellular superoxide radicals was doubled in extracellular SOD-null corneas, and the endothelial cell density decreased more with age in extracellular SOD-null than in wild-type control cornea.

The cornea, protects the inner parts of the eye against the damaging effect of UV rays particularly of shorter wavelength (UVC, UVB), and the reactive oxygen species generated by them $[27,28]$. This is possible due to effective low-molecular 
weight antioxidants (such as ascorbic acid, glutathione, alphatocopherol) $[29,30]$ as well as high molecular weight antioxidants (such as superoxide dismutase, glutathione peroxidase and reductase, catalase) [11].

According to Joyce [31], the comeal endothelium is the single-cell layer that forms a physical barrier between the corneal stroma and aqueous humour. The barrier and ionic 'pump' functions of corneal endothelium help regulate stromal hydration. Loss of endothelial cells due to increasing age can reduce the density of endothelial cells to a critical point below which the stroma becomes edematous and visual acuity is affected.

Also, immunohistochemical study revealed intense expression of caspase 3 within the basal epithelium reflecting increased apoptic rates as well as comparative reduction of GFAP in stoma and endothelium of $30 \mathrm{M}$-old rats. The cornea is one of the most sensitive tissues of the body, as it is densely innervated with sensory nerve fib ers via the ophthalmic division of the trigeminal nerve by way of 70-80 long ciliary nerves and short ciliary nerves. Research suggests the density of pain receptors in the comea is 300-600 times greater than skin [32]. Most of the corneal nerve fibres are sensory in origin and are derived from the trigeminal nerve; however, in some cases the inferior cornea receives some of its innervation from the maxillary branch of the trigeminal [33]. On the other hand, 30M.aged rat exhibited decreased expression of GFAP comparing with young age suggesting that nerve ending might play some role in deterioration of corneal function. Previously Studies mentioned that aging cause vacuolation and degeneration of nerve axon [34]. The trigeminal nerve (cranial nerve $\mathrm{V}$ ) or its branches represent the main nerve supply of the cornea may reveal neurotrophic keratopathy leading to impaining of vision during aging. Corneal dysfunction of diabetic retinopathy involved reduction of density and nerve fiber length [35].

The author finally concluded that aging contributed to an increase of corneal damage as expressed by increase of apoptosis, decreased GFAP expression as well as alterations of BAX,TGF and CD45 which are parallel with increase cell death and different pathological alterations in the epithelium, stroma and endothelial layers that contributed to severe effects on the vision acuity of individuals.

\section{References}

[1]. Rose, M.R.1991. Evolutionary biology of aging. Oxford: Oxford University Press.

[2]. Greiner, J.V., Kenyon, K.R .,1994. In: Albert DM, Jakobiec FA, eds. Principles and practice of ophthalmology-basic sciences. Chapter 52. Philadelphia: WB Saunders.

[3]. Moosavi, M., Sareshtedar, A., Zarei-Ghanavati, S. Zarei-Ghanavatim, M., Ramezanfar, N. 2010. Risk factors for senile corneal arcus in patients with acute myocardial infarction. J. Ophthalmic Vis. Res. 5(4),228-231.

[4]. Hickey, N., Maurer, B., Mulcahy, R.,1970. Arcus senilis: its relation to certain attributes and risk factors in patients with coronary artery disease. Br Heart J 32,449-452.

[5]. Chua, B.E., Mitchell, P., Wang, J.J.,2004. Rochtchina E. Comeal arcus and hyperlipidemia: findings from an older population. Am J Ophthalmol;137:363-365.

[6]. Pajoohesh-Ganji, A., Stepp, M.A.,2005. In search of markers for the stem cells of the corneal epithelium. Biol. Cell 97, 265-276.

[7]. Ehlers, N., Hjortdal, J., 2006. The cornea, epithelium and stroma. Adv Organ Biol 10, 83-111.

[8]. Galgauskas, S., Noryydaitè, D., Krasauskaitè, D., Stech, S., Ašoklis, R.S.,2013. Age-related changes in corneal thickness and endothelial characteristics. Clinical Interventions Aging 8,1445-1450.

[9]. Yang, Y., Hong, J., Deng, S.X., Xu, J.2014. Age-related changes in human comeal epithelial thickness measured with anterior segment optical coherence tomography. In vest Ophthalmol Vis Sci 55(8),5032-5038.

[10]. Grossniklaus, H.E., Nickerson, J.M., Edelhauser, H.F., Bergman, L.A., Berglin, L., 2013. Anatomic alterations in aging and age-related diseases of the eye. Invest. Ophthalmol. Vis. Sci. 54(14),ORSF23-27.

[11]. Cejková, J., Vejrazka, M., Pláteník, J., Stípek, S.,2004. Age-related changes in superoxide dismutase, glutathione peroxidase, catalase and xanthine oxidoreductase/xanthine oxidase activities in the rabbit comea. Exp Gerontol 39(10),:1537-1543

[12]. Hillenar, I., van Cleynenbreuge, I.H., Remeijer, L. 2012. How nomal is the transparent cornea? Effects of aging on corneal morphology. Ophthalmology 119(2),241-8.

[13]. Daxer, A., Misof, K., Grabner, B., Ettl, A., Fratzl, P.,1998. Collagen fibrils in the human corneal stroma: structure and aging. Invest. Ophthalmol. Vis. Sci. 39(3),644-648.

[14]. Jun, A.S., Chakravarti, S., Edelhauser, H.F., Kimos, M.,2006. Aging changes of mouse comeal endothelium and Descemet's membrane. Exp. Eye Res 83(4), 890-896.

[15]. Waring,G.O.,Bourne,W.M., Edelhauser,H.F., and Kenyon,K.R.(1982).The corneal endothelium. Normal and pathologic structure and function. Ophthalmology 89, 531-590.

[16]. Rhim, J.H., Kim, J.H., Yeo, E.J., Kim, J.C., Park, S.C. 2010. Caveolin-1 as a novel indicator of wound-healing capacity in aged human corneal epithelium. Mol. Med. 16(11-12),527-34. 
[17]. Hodge, S.J., Hodge, G.L., Reynolds, P.N., Scicchitano, R., Holmes, M.2003. Increased production of TGF-B and apoptosis of T lymphocytes isolated from peripheral blood in COPD. Am. J. Physiol. Lung Cell Mol. Physiol. 285, L492-L499.

[18]. Bright, J.J., Kerr, L.D., Sriram, S.,1997. TGF-beta inhibits IL-2- induced tyrosine phosphorylation and activation of Jak-1 and Stat 5 in T lymphocytes. Journal Immunolology 159: 175-183.

[19]. Szentmáry, N., Stündl , A., Szende, B., Süveges, I. 2010. P21, p27, bax, cathepsin and survivin pathways in macular dys trophy corneas. His tology His topathology 25(3),287-90.

[20]. Li, Q.J., Ashraf, M.F., Shen, D.F., Green, R., Stark, W.J. et al.2001. The role of apoptosis in the pathogenesis of Fuchs endothelial dystrophy of the cornea._Arch. Ophthalmol. 119(11), 1597-604.

[21]. Ritchey, E.R., Code, K., Zelinka, C.P., Scott, M.A., Fischer, A.J.2011. The chicken cornea as a model of wound healing and neuronal re-innervation. Mol. Vision 17,2440-2454.

[22]. Ferrari, G., François, J., Feher, J.,1973. Arcus senilis. Doc Ophthalmol. 34(1),165-182.

[23] Ibrahim, O.M., Kojima, T., Wakamatsu, T.H., Dogru, M., Matsumoto, Y., Ogawa, Y., Ogawa, J., Negishi, K., Shimazaki, J., Sakamoto, Y., Sasaki, H., Tsubota, K.,2012. Comeal and retinal effects of ultraviolet-B exposure in a soft contact lens mouse model. Invest. Ophthalmol. Vis. Sci. 53(4),2403-13.

[24]. Joyce, N.C., Harris, D.L., Zhu ,C.C. 2011. Age-related gene response of human comeal endothelium to oxidative stress and DNA damage. Invest. Ophthalmol. Vis. Sci. 52(3),1641-1649.

[25]. Behndig, A., Karlsson, K., Brännström, T., Sentman, M.L., Marklund, S.L. 2001. Corneal endothelial integrity in mice lacking extracellular superoxide dismutase. Invest. Ophthalmol. Vis. Sci. 42(12),2784-2788.

[26]. Behndig, A.,2008. Comeal endothelial integrity in aging mice lacking superoxide dismutase-1 and/or superoxide dismutase-3. Molecular Vision 14,2025-2030.

[27]. Klamt, F., Dal-Pizzol, F., Bernard, E.A., Moreira, J.C.,2003. Enhanced UV-mediated free radical generation; DNA and mitochondrial damage caused by retinol supplementation. Photochem Photobiol Sci 2, 856-860.

[28]. Beak, S.M., Lee, Y.S., Kim, J.A.2004. NADPH oxidase and cyclooxygenase mediate the ultraviolet B-induced generation of reactive oxygen species and activation of nuclear factor-kB in HaCaT human keratinocytes. Biochimie 86, 425- 429.

[29]. Lee, S.M., Koh.H.J., Park, D.C., Song, B.J., Huh, T.L., Park, J.W.2002. Cytosolic NADP(+)-dependent isocitrate dehydrogenase status modulates oxidative damage to cells. Free Radic Biol Med 32, 1185-1196.

[30]. Ayala, M.N., Soderberg, P.G. 2004. Vitamin E can protect against ultraviolet radiation -induced cataract in albino rats. Ophthalmic Research 36, 264-269.

[31]. Joyce, N.C.2005. Cell cycle status in human comeal endothelium. Exp. Eye Res. 81(6),629-638.

[32]. Carlos, B., Juana, G. ,1996. Corneal Nociceptors. Neurobiology of Nociceptors. Oxford University Press. p. 146.

[33]. Ruskell, G.L.,1974. Ocular fibers of the maxillary nerves in monkey. J. Anat. Lond. 118, 195-203.

[34]. El-Sayyad, H.I.H., Khalifa, S.A., El-Sayyad, F.I., Al-Gebaly, A.S. El-Mansy, A.A., Mohammed, E.A.M. ,2014. Agingrelated changes of optic nerve of Wistar albino rats. Age (Dordr). 36(2),519-32.

[35]. Bitirgen, G., Ozkagnici, A., Malik, R.A., Kerimoglu, H. ,2014.Corneal nerve fibre damage precedes diabetic retinopathy in patients with type 2 diabetes mellitus. Diabetic Medicine. 31(4),431-8.

Table 1. Flow cytometry of percentages of apoptosis, BAX, TGF-B and CD45 of cornea during aging of Wistar rats.

\begin{tabular}{|c|c|c|c|c|}
\hline & $\begin{array}{c}\text { M1 (sub G0/G1 } \\
\text { apoptosis) }\end{array}$ & Bax & TGF-B & CD45 \\
\hline $6 M$ & $12.99 \pm 0.74^{*}$ & $17.39 \pm 1.85^{\star}$ & $31.51 \pm 1.11^{*}$ & $17.20 \pm 0.99$ \\
\hline $18 M$ & $23.93 \pm 1.24^{\star}$ & $30.86 \pm 1.61^{\star}$ & $36.93 \pm 0.62^{\star}$ & $20.49 \pm 1.09^{* \star}$ \\
\hline $24 \mathrm{M}$ & $46.19 \pm 2.5 \cdot * \star$ & $42.10 \pm 1.85^{\star \star}$ & $39.92 \pm 1.17^{\star}$ & $36.04 \pm 1.14^{*}$ \\
\hline $30 \mathrm{M}$ & $72.49 \pm 2.05^{\star \star}$ & $54.82 \pm 1.75^{\star \star}$ & $44.21 \pm 1.67^{\star \star}$ & $45.27 \pm 1.26^{*}$ \\
\hline F-test & 213.86 & 80.941 & 19.718 & 121.185 \\
\hline$P<0.05$ & s. & s. & s. & s. \\
\hline
\end{tabular}


Data are represented by the mean \pm SE $(n=5)$. M1-M4 phases of cell cycles represented as percentages of total $100 \%$. ${ }^{* *}$ Significant at $\mathrm{P}<0.05$.

3
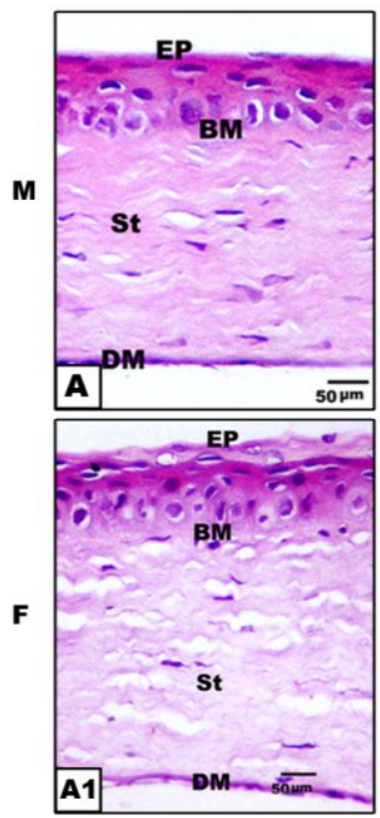

6
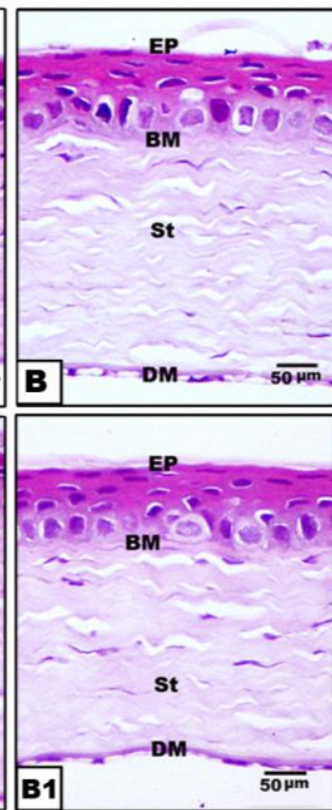

18

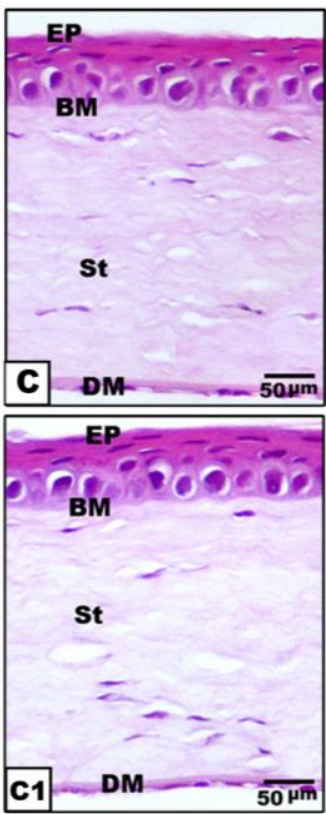

24
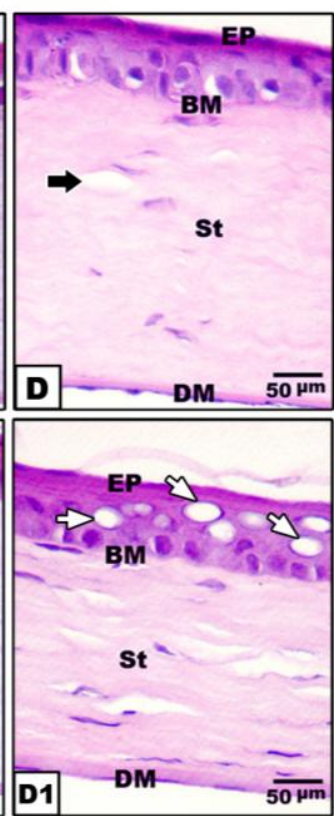

30
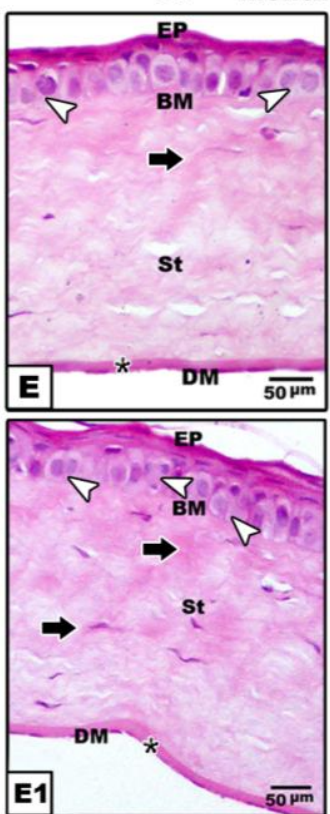

Fig.1. Photomicrographs of histological sections of 3- (A,A1), 6- (B-B1) , 18-(C-C1), 24-(D-D1) and 30-M-old (E-E1) rats. Male (A-E) and female (A1-E1). 3-18M-old show regular pattern of corneal epithelium with underlying Bowman's layer. The corneal stroma characterized by fine distribution of keratocytes and lined intemally with continuous sheath Descemet's membrane. In old age,note abundant vacuoles within epithelium of 24M-old females (D1)and both increase mitotic figure and hyalinized degenerated stroma in 30M-old(E-E1). Abbreviations; Ep, Epithelium; BM, Basement membrane; St, Stroma; DM, Descemet's membrane. HX-E

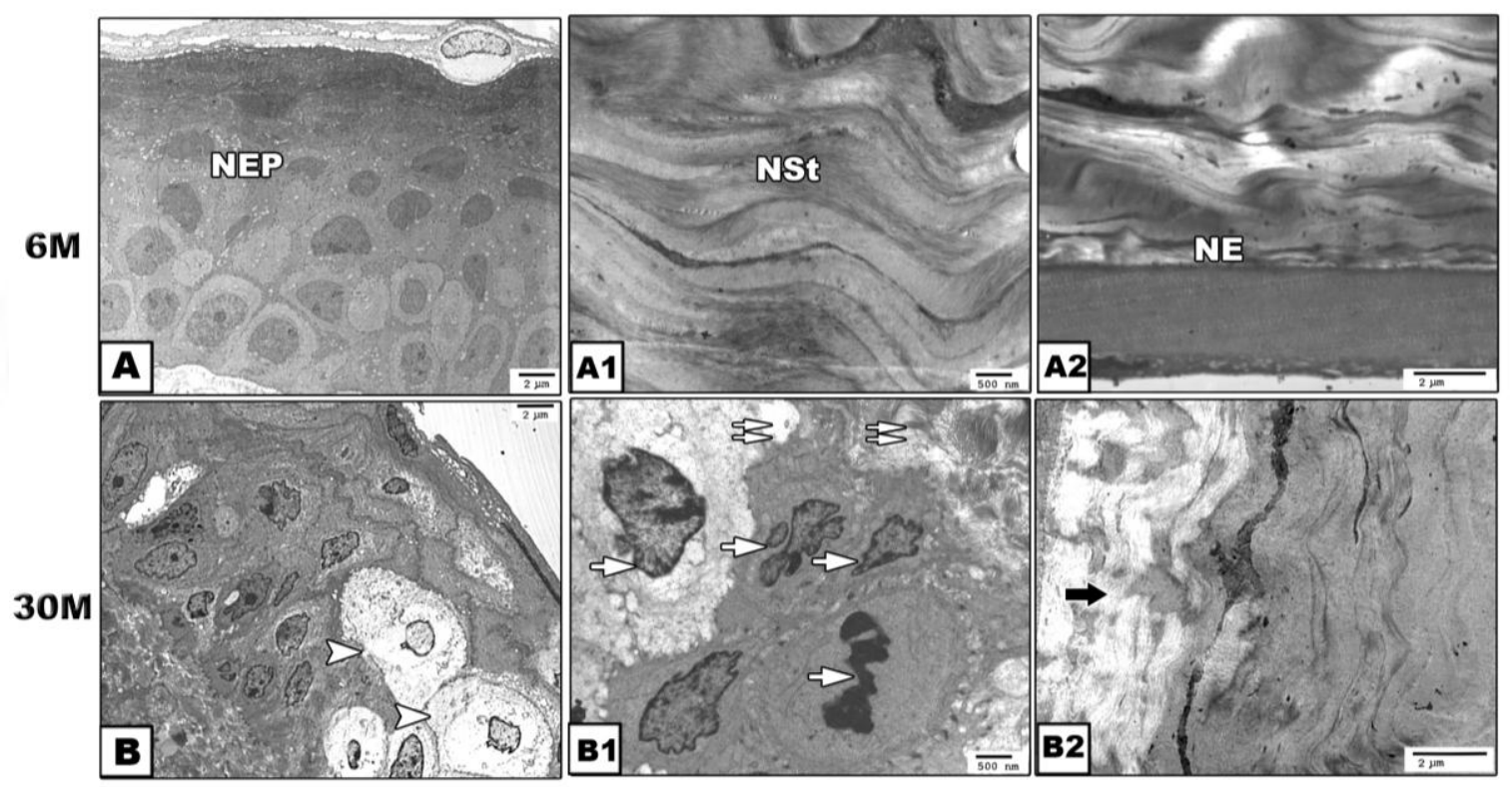

Fig.2. Transmission electron micrographs of 6- (A-A2) and 30-month-old (B-B2) rats. Note vacuolar degeneration of epithelial cell of $30 \mathrm{M}$-old (Fig. B, small arrow head) comparing with nomal epithelium in 6M-old (NEP Fig.A) in 6Mold. The stroma appear necrotic with apoptic keratocytes in 30M-old(Fig.B1,narrow arrow) comparing with nomal stromain 6M-old (NSt). The endothelium shows apparent necrosis in 30M-old (Fig. B2, black arrow) comparing with nomal endothelium in 6 M-old(Fig.A2, NE). Lead citrate and uranyl acetate 

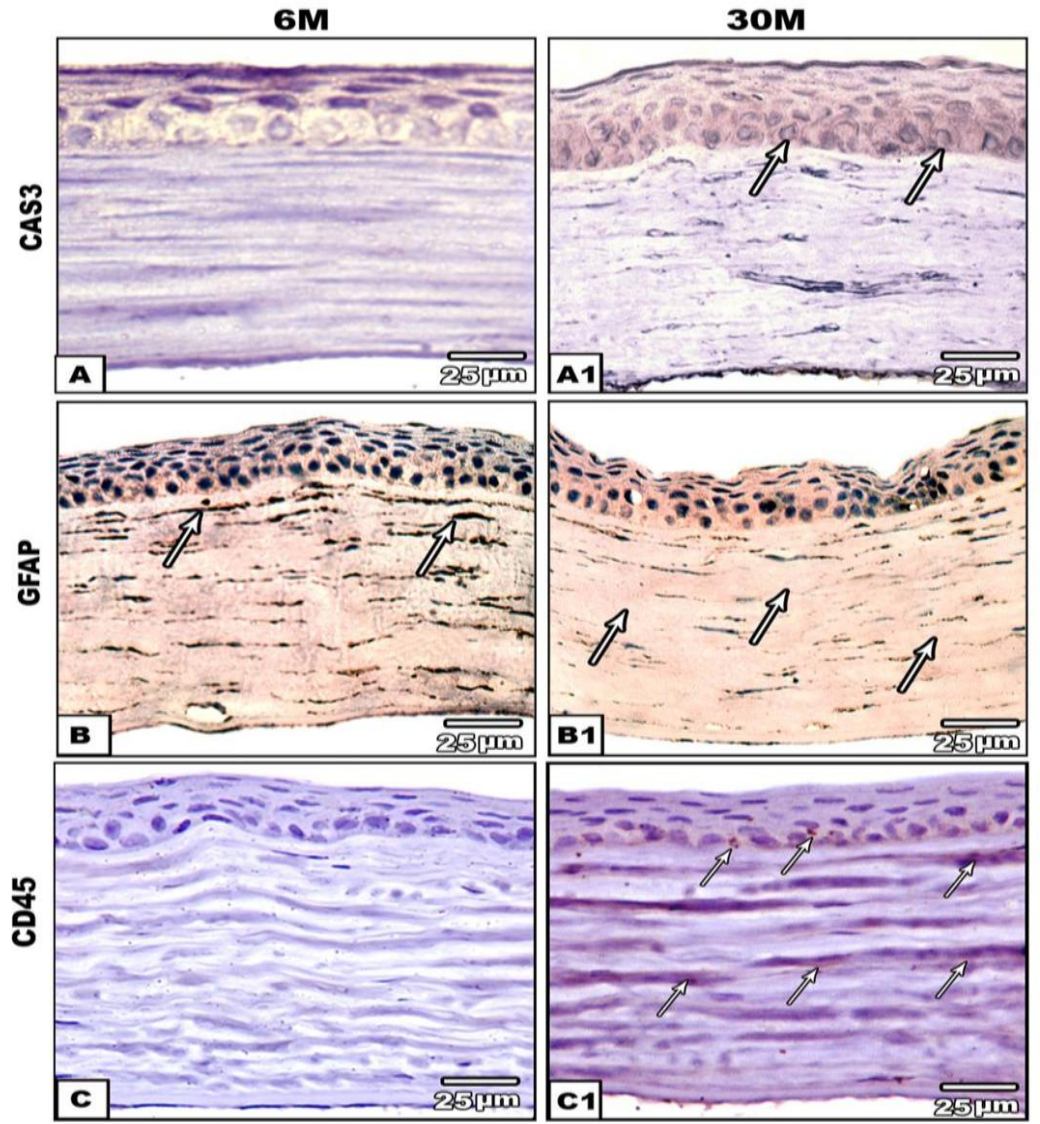

Fig. 3 Photomicrographs of formalin-fixed, paraffin-embedded comea stained with the antibody of caspase 3 (A-A1), GFAP (B-B1) and CD45 (C-C1) of 6-M-old (A-C) and 30-month-old (A1-C1) rats. 30M-old rat showing positive immuno-reactive caspase 3 (arrow) of epithelial basal cells manifesting apoptosis as well as positive immunoreactive CD45(arrow) of both epithelium basal and stromal tissue comparing with negative staining in young age. GFAP showed intense immuno-reactive activity in stromal tissue (arrow).
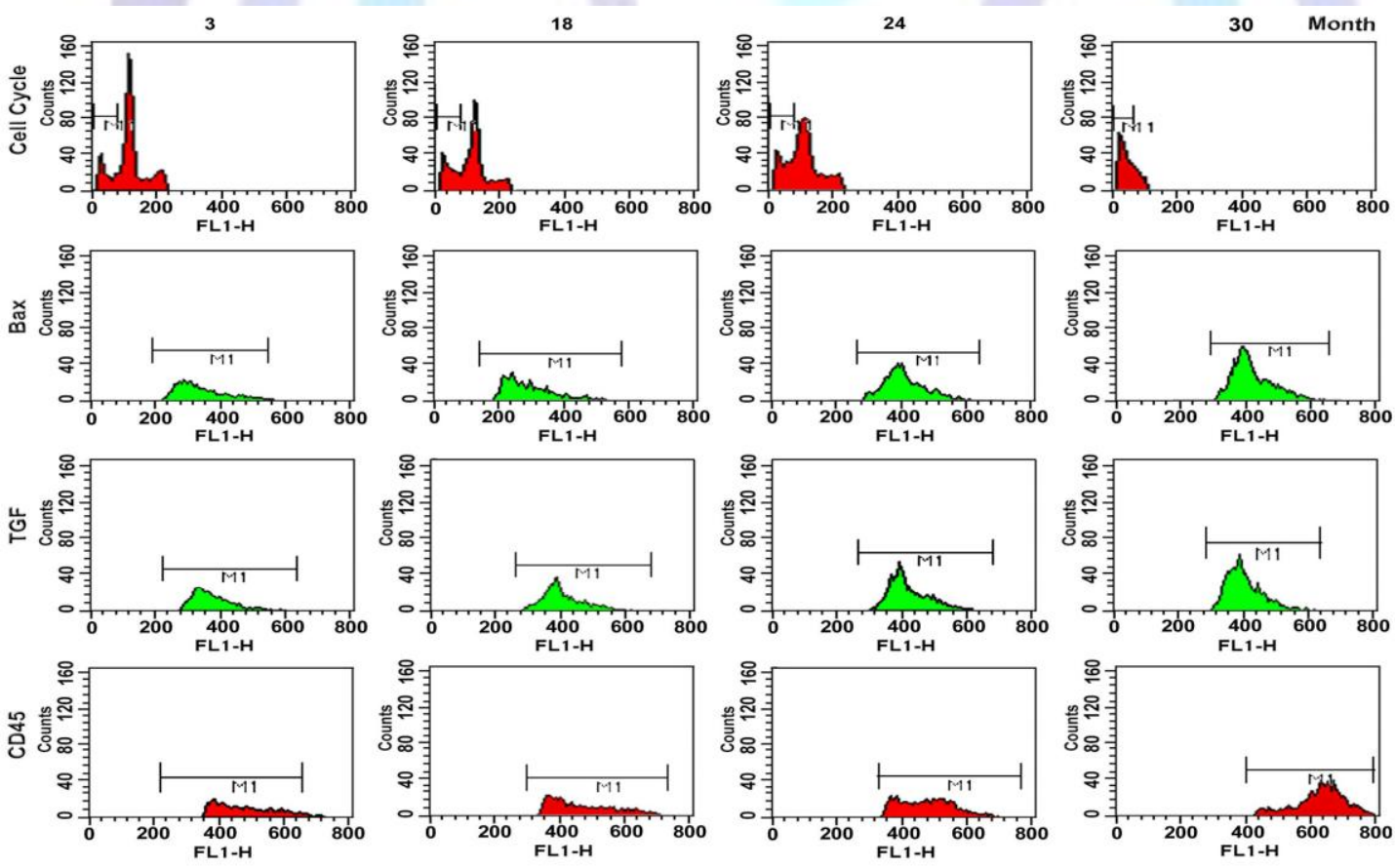

Fig. 4. Flow cytometry chart of DNA, Bax, TGF and CD45 of cornea of Wistar rat aged 6, 18, 24, and 30 months. CD45 show marked decrease, meanwhile M1 apoptosis, Bax, TGF show marked increase. FL1 detector, fluorescence.

FL2 detector, fluorescence of propidium iodide stain phycoerythrin orange (PI). 